\title{
Interchangeable Concept of Cognitive Styles and Learning Styles: a Conceptual Analysis
}

\author{
Zainudin Abu Bakar ${ }^{1}$, Rafaquat $\mathrm{Ali}^{2}$ \\ ${ }^{1}$ Faculty of Education, Universiti Teknologi Malaysia, Malaysia \\ ${ }^{2}$ Department of Education, Bahawalnagar Campus, Islamia University of Bahawalpur, Pakistan
}

\section{Article Info \\ Article history: \\ Received June 4, 2017 \\ Revised Sep 29, 2017 \\ Accepted Apr 22, 2018}

\section{Keywords:}

Cognitive Style

Learning Style

Student's Learning

\begin{abstract}
Inquiries into the nature and effects of cognitive and learning style constructs are mounting daily, regardless of criticism and confusion about the boundaries, natures and to some extent overlapping issues of these two constructs. These issues raise several questions about the credibility of these two constructs with regard to further research, application and development. Therefore, there is a need to crystallize their natures to pave the way for further research and for a better understanding of individual's learning. The current scientific review strengthens the concept of these two constructs as separate and independent, each contributing in its own way to different fields of human learning. Both constructs have different histories and schools of thought directed toward different ends. The relationship of these constructs undeniably establishes their usefulness and value as research subjects. However, specific concerns is required in defining cognitive and learning styles which may hinder the credibility and usefulness of further research, including valid and reliable measurements, cohesive theory, application oriented studies, use of multiple methods in research, and the origin and development of these constructs. This article explores the discourse in these fields and highlights potential issues with the constructs to assist researchers in constructing a more comprehensive understanding of the research framework.
\end{abstract}

Copyright $\odot 2018$ Institute of Advanced Engineering and Science. All rights reserved.

\section{Corresponding Author:}

Zainudin Abu Bakar, Faculty of Education, Universiti Teknologi Malaysia, 81310 Johor Bahru, Johor, Malaysia. Email: p-zain@utm.my

\section{INTRODUCTION}

Research on cognitive and learning styles has triggered a variety of discourses due to its extensive use in applied situations in management, education, psychology and medicine. The term, which originated in psychology, has been widely used in education, management, and medicine. The complexity later resulted in an incoherent and disjointed body of knowledge, frameworks, and theoretical styles. Kozhevnikove described the prevailing attitude and behavior of researchers and practitioners as follows: "The paradox of the current situation is that, interest in building a coherent theory of cognitive styles remains at a low level among researchers in the cognitive sciences [1]". This dispersed work by researchers from different disciplines and regions has created many overlapping concepts and terms with regard to cognition and learning, and there is a need to develop a coherent and unified body of knowledge [2].

As cited in Cools and Bellens, Sadler-Smith remarked that "different authors used the concept such as cognitive styles, learning styles and learning preferences randomly and interchangeably and there seems to be no consensus how these concepts are interrelated [3], [4]". Cassidy and Smith also argued that research conducted in an applied and practical sense, without considering the meaning of psychological terms, will 
create confusion and misunderstanding, which may lead us away from basic psychological theories and concepts [5], [6].

This article is trying to highlight several concerns regarding the cognitive style and learning style discourse. A scientific review is used to explore studies on the styles which cover the application of the concept especially in learning and teaching processes. Specific elements and constructs are highlighted in order to underline the differences and similarities of the concept which has long been discussed as an interchangeable concept. The discussion is done by highlighting the cognitive style in perspective followed by the learning style. The teaching and learning process is used to highlight how the concept is very much so closely related. At the end of the discussion the important point of both concepts are highlighted to show how these can interchangeably be used in the context of research in education. The article is concluded by providing concluding remark for further researchers.

\section{COGNITIVE STYLE IN PERSPECTIVE}

Ausburn and Ausburn described cognitive styles as individuals' consistent psychological representations/characteristics/elements, governed and linked cognitively to information acquisition and its processing in perception, thinking, problem solving, and imagery, with quantitative and qualitative variation. In this sense, it has dual functions, including organization and control of cognitive process and related resources [7]. Shade additionally included the personality element, which represents the superordinate construct that accounts for individual preferences in various cognitive, perceptual and personality dimensions that influence differences in information processing [8]. Messick argued that cognitive styles organize the resources related to cognition of situations and also to regulation and control of the cognitive process in a learning situation which incorporated by learners [9], 10]. However, given the unique nature of cognitive styles, these processes cannot depend on personality and can be considered as independent of ability and personality [11].

Kozhevnikove suggested differences in cognitive style as heuristics that can be classified with regard to their regulatory functions in information processing, from perception to metacognitive processing of environmental information [1]. There are many levels of information processing. There are different types of control regulation at each level of information processing, ranging from reception of information to utilization at the end of processing. During the thinking process, there is a consistent approach to organization and to information processing that is independent of intelligence and is responsible for differences in ways of thinking quantitatively and qualitatively [12]. These are cognition-based consistent differences that force an individual to exhibit a particular way of thinking. The particular way of thinking depends on how that person perceives, processes, and remembers information in relation to others.

In the context of learning, cognitive style is regarded as an individual difference that is important to student's success. As mentioned above, cognitive style is independent of personality, ability, intelligence, learning style and learning strategies, but indirectly affects a range of motor skills [6], [11, [13], [14]. Cognitive styles' independence from important variables demands special treatment in teaching and learning situations. Therefore, learning materials and teaching approaches should match the cognitive styles of students to ensure maximum learning and better learning outcomes [1]. The match between instructional materials and students' cognitive styles has improved students' learning outcomes [15].

With regard to academic performance, Tinajero, Lemos, Araujo, Ferraces, \& Paramo found that cognitive styles and learning strategies were significant contributors to academic achievements [16]. Fieldindependent students performed consistently better than their counterpart field-dependent students in academic achievements and problem solving (when problems ranged widely in their complexity) [17-19].

Similarly, analyzed the records of pupils in special schools and found out that cognitive styles affect behavior [6]. It was determined that students' social behavior varies depending on their different cognitive styles. Although there was variation in social/behavioral problems associated with different cognitive styles, training designs should be adjusted based on different cognitive styles to make the learning process more effective and efficient because different interactions between a student's cognitive style and teaching methods pave the way for student conduct and learning behavior [12], [20]. The student's performance in different subjects is also affected by his or her cognitive style. For instance, holistic imagers and analytic verbalizers showed superior performance to holistic verbalizers and analytic imagers in the subject of science.

There is evidence that considerations of cognitive style are crucial to teaching and learning effectiveness and are also responsible for learning outcomes, independent of other factors such as cognitive skills and intelligence [13], [21]. Most literature supports the importance of matching cognitive styles in teaching and learning in schools. However, some literature supports the mismatching of cognitive styles in teaching and learning, arguing that this will challenge students, help them to overcome their style 
weaknesses, and prepare them for real life mismatching situations [15]. Certain assessment procedures favor certain cognitive styles [22]. Martinsen \& Diseth highlighted the correlation of scores on the AssimilatorExplorer Inventory with preferences for novelty seeking behavior, rules and planning behavior [23].

With regard to brain activities, it has been proven that cognitive style differences are supported by neurophysiological and basic brain differences. Huang \& Byrne identified the relation of analytic and holistic cognitive styles to hemispheric activity through the lateral eye movement paradigm [24]. Oliveri noted the general role of the parietal lobe and subcortical structures in the verbalizer and visualizer thinking/cognitive styles [25]. Hence, the role of cognitive styles in multi-linguistic knowledge/ability was found to relate to cognitive style preferences. The ability to apply the grammatical rules of a second language is influenced by field-dependent preference [26].

The use of multimedia and the internet in learning and training situations-specifically for educational purposes-is increasing every day. Advancements in information technology can help to meet the individual needs of students. Recently, researchers have linked the notion of cognitive styles to computer programming and software development, which has made the idea of the cognitive style a more practical construct [27]. Angeli observed significant differences in the performance of field-dependent, field-independent and mixed learners who solved a complex problem through computer modeling and found out that the use of hypermedia learning systems that matched cognitive style preferences improved the learning and perception of students [20], [28]. Studies concerning the applicability of cognitive styles show that movement will enhance students' learning, which means that it cannot be neglected or overlooked.

\section{LEARNING STYLE IN PERSPECTIVE}

Individuals show differences in the ways in which they interact with their learning environments. These differences affect everything from interaction with the learning material (behaviorally) to final storage of information (cognitively) for future reference or use. In general, these learning differences are regarded as learning styles. Bird, Romanelli, \& Ryan define learning styles as a distinctive psychosocial, affective and cognitive behaviors that give rise to relatively stable measures of the perception of, interaction with and response to the surrounding learning environment [29]. Unique learning styles remain relatively stable even when they encounter different tasks/situations [30]. In other words, when people face a learning situation (stimulus) in a learning environment, they respond in their own way. So, a learning style is an individual's way of receiving and responding to a learning stimulus with a unique set of psychological, affective and cognitive behaviors. A learning style can be referred to as an "individual's preferred mode of receiving and processing information," which cannot distinguish it from a cognitive style. The concepts of cognitive and learning styles detach at the following point: "cognitive style involves cognition based process, whereas learning style is rooted in exterior behavior and response to learning situation" [31].

Honey \& Mumford and Kolb argued that a learning style is an individual's preference for understanding and transforming his/her experiences [32]. Vermunt \& Vermetten used the term "learning style" in a more elaborate way, regarding it as a superordinate concept in which the cognitive and affective processing of subject matter, the metacognitive regulation of learning, and conceptions of learning and learning orientations are united. In other words, it is related to preferences in interacting, receiving, processing and responding cognitively and affectively in a learning situation, independently of the task encountered [33].

Researchers have debated the theoretical validity of different learning styles. Slack \& Norwich conducted a study of the theoretical justification of the [34]. Pupils' self-reported inventories were used for the exploration of their learning styles. They claimed that this model lacks theoretical background and justification for labeling the auditory, kinesthetic and visual styles. Schmeck and Raynolds cautioned against overgeneralizing learning styles into mutually exclusive styles, which can lead to incorrect expectations of pupils [34]. Arrangements made on the basis of these mutually exclusive styles can lead to ineffective learning opportunities. Miller considered LSI (Learning Style Inventory) a poor instrument in terms of measurement [35]. Reio examined the psychometric properties of the Gregoric Style Delineator (GSD) and found statistically little support for its theoretical basis/design and concomitant portrayal of one's cognitive learning style [36].

Bergsteiner, Avery, \& Neumann applied standard modeling categorization criteria to Kolb's basic model, which alone was used in 990 studies from 1971-1999 [37], [38]. The researchers claimed to identify errors in fundamental graphic syntax, inability to pass the modeler's graphic sufficiency and simplification tests, and problems related to categorization and definitions [37].

With regard to studies of the identification of learning styles, Platsidou \& Metallidou investigated the psychometric strengths of the Kolb learning style inventory and Felder and Solomon's Index of Learning Style [39]. A Greek sample using the LSI revealed satisfactory reliability and weak construct validity. There 
were strong preferences for only accommodative and divergent learning styles. The ILS only achieved an acceptable level of reliability on ability of discrimination and construct validity. The study suggested that these two instruments cannot be used for grouping students with reference to their learning styles; they can only be used to encourage the self-assessment of an individual. Brew reported on the gender sensitivity of the Kolb LSI (1985) for a sample of Australian university students [40].

Similarly, Reio examined the psychometric properties of the Gregoric Style Delineator (GSD) and found little statistical support for the GSD's theoretical basis/design and portrayal of an individual's cognitive learning style [36]. Slack \& Norwich, in a classroom based study, reported internal and retest unreliability of the kinesthetic learning scale's auditory, kinesthetic and visual learning style inventory [34]. Zwanenberg, Wilkinson, \& Anderson also found that the reliability of two famous learning style descriptors: Felder \& Silverman's index of learning and Honey \& Mumford's learning style questionnaire [41]. The ILS was found to mix both cognitive and learning style characteristics and measured absolutely none of either. They advised not using it for anyone other than engineering students, for whom it was intended. The LSQ was found to be more reliable internally than the ILS. It was also unable to possess predictability and was not up to the standard of psychometric instruments. Busato, Prins, Elshout, \& Hamaker argued that Vermunt's learning styles do not have sufficient evidence to justify tailoring higher education to them, and suggested further research to validate these styles [42].

The learning style construct has been criticized by some researchers and practitioners. Riener \& Willingham considered learning styles practically inapplicable and useless and called them a myth [43]. Leite, Svinicki, \& Shi evaluated the VARK learning style inventory (Visual, Aural, Read/Write and Kinesthetic) and reported some flaws, such as poor item selection and construction [44]. Rohrer \& Pashler opposed tailoring instruction to students' different learning styles [45]. Rohrer \& Pashler also argued that there is no empirical support for this expensive tailoring of instruction to learning styles [45]. Norman claimed that the concept of learning styles is obsolete and has very little to do with learning [46].

The opposing arguments give the impression that learning style research has no validity and is unable to help researchers in improving learning overall. However, when we assessed the validity of these claims, we were surprised that they noted flaws mostly in one aspect, concept or dimension of learning styles. Riener and Willingham: Visual, Kinesthetic and auditory; Leite et al.: Visual, Aural, Read/write and Kinesthetic; and Norman: Visual, Verbal Taxonomy [43], [44], [46]. They neglected a massive literature supporting the learning style concept and movement. Here we will present some literature that supports the movement. Kolb and Boyatzis indicated the potential of research on learning styles by noting that for experiential learning theory and learning style inventory alone, there were 990 publications from 1971-1999 [38].

There are many studies supporting the claim that students' achievements increase as a result of matching between learning styles and teaching methods [47]. Learning is a characteristic just like other developmental and biological characteristics [48]. which means that it cannot be neglected. There are significant differences in learning styles in students of different disciplines [49]. Students' learning patterns can explain the variance in their academic performance [50] and is also related to personality types [51].

Matching learning styles to teaching methods increased students' retention ability [34]. Vermunt \& Vermetten described how learning outcomes are affected by learning orientations [33]. Akbulut \& Cardak and Lurea, Neascsu, Safta, \& Suditu claimed that adaptive educational hypermedia models that were based on learning styles enhanced students' success and satisfaction [52,53]. Miller identified 40 publications that found significant effects with the Gregoric Style Delineator (GSD) and showing that computer based instruction in reference to GSD learning style improved students' learning [35].

In cases of mismatch, students faced problems in their interactions with courses/ learning situations [54]. Ozgur, Temel, \& Yilmaz verified the relationship between problem solving abilities and the assimilator and converger styles on the Kolb LSI, whereas Mehrdad \& Ahghar found a relationship between individuals' visual orientations/styles and their uses of learning strategies [55], [56]. In a different mode, Huang, Wu, Yang, \& Hwang developed a portfolio-based programming learning style diagnosis system for Felder's learning style [57]. There is evidence of a relationship between learning styles on the Kolb LSI and demographic data, which can explain the underlying factors [58].

Law \& Meyer credited the ILS Vermont with differentiating students' learning styles along an inventory of learning styles' dimensions [59]. In favor of learning styles, Hurst-Wajszczuk argued that teachers can shape their teaching to minimize their own learning styles' negative effects on students [60].

Alaoutinen, Heikkinen, \& Porras utilized an intensive collaborative teaching concept, CODE CAMP, to demonstrate the effect of learning styles [61]. The study indicated an increased motivation to learn among reflective- intuitive students [62]. Later, Graf, Liu, Kinshuk, Chen, \& Yang demonstrated that working memory capacity is connected to learning styles [63]. Cook, Thompson, Thomas, \& Thomas found empirical support for the theoretical model of Vermunt's learning style inventory [64]. Cook \& Smith found 
the ILS (Index of learning styles) to be a valid instrument for measuring learning styles and concluded that cognitive style and learning style scores may not be interchangeable, even for constructs with similar definitions, due to their being different constructs [65].

Vermunt \& Vermetten recommended incorporating the interplay between affective and social/collaborative learning and between self-regulation and external regulation, as well as promotion of more favorable learning patterns in different types of learning environments [39]. It is imperative that the application of learning style theory and research continues to hold great promise for practitioners in both in education and training as a potentially powerful mechanism for enabling pupils, students and trainers to manage their own learning better throughout their educational and working lives [66]. As such, it is concluded that the role of learning styles cannot be neglected in either classroom settings or lifelong learning.

\section{THE INTERCHANGEABILITY OF CONCEPTS AND PERSPECTIVES}

The terms cognitive and learning styles have been used interchangeably without any discrimination in the literature [67]. Smith conducted a study that supported the independent nature of cognitive styles with regard to learning styles and learning strategies; these concepts measure different constructs regardless of the fact that they include many similar styles [6], [65]. On many occasions, the term learning style is imprecisely used as an umbrella term for both cognitive and learning styles [67]. Hartley distinguishes between the two terms: a cognitive style is characteristically an approach to different cognitive tasks, whereas a learning style is characteristically an approach to different learning tasks [5].

There are also differences in terms of the nature and the number of style elements. The majority of cognitive style models present bipolar styles discussed in theoretical or academic research. As such, most learning styles deviate from this bipolar model and are discussed in the context of their practical applications [68]. Cognitive styles are more structured and are not dependent on learning situations in the same way as learning styles [5]. As both are developed based on different theoretical perspectives, scores for these measurements cannot be exchanged for constructs with similar labels and definitions [65]. Cognitive styles include multiple cognitive processes such as problem solving, thinking, and remembering, which are distinct and rare components of learning styles [34]. Thus, we can say that an individual's distinctive and typical overall way of cognitive processing is a cognitive style, whereas his or her characteristic mode or way of learning in a learning situation is called a learning style.

Evans et al. differentiated between the two terms: cognitive styles are considered to be individual differences in processing that are integrally linked to a person's cognitive system (the person's preferred way of processing) [67]. According to Peterson, Armstrong \& Rayner, these are partially fixed, relatively stable and possibly innate preferences [69]. From this perspective, learning styles were described as an individual's preferred way of responding (cognitively and behaviorally) to learning tasks that change depending on the environment and context and thus are seen as malleable. Armstrong, Peterson and Rayner conclude that cognitive styles are individual differences in preferred ways of processing information through cognitive brain-based mechanisms and structures [70]. Perceiving, organizing and analyzing information are examples of such processing. These influence the behavior of the individual. These seem to be relatively stable and possibly innate. Learning styles are the individual's preferred ways of responding and have cognitive and behavioral dimensions. They may change with the environment and context. They affect motivation and attitude toward learning and determine performance. Nevertheless, Smith verified that learning style and cognitive style are independent of each other and different as constructs [4]. As such, different approaches and treatments are required to reveal the mysteries of human learning.

An excess of different learning styles, definitions, and measurement instruments has baffled researchers and practitioners, policy makers, and novices in the field. Better knowledge of learning styles, accompanied by advancements in information technology, could benefit the learning experiences of different types of students in large classes. Limited research confirming the relationship between learning styles and learning outcomes has resulted in opposition and hesitation to apply learning style research beyond experiments in actual classroom settings [51]. Learning style researchers should focus on the following aspects to make learning style research more practical and valid.

According to Wong, learning styles are not culturally structured but rather are contextual [71]. We may infer that learning styles tend to be modified by experience, context and exposure. This argument is supported by many studies. Vermunt found that students' learning patterns on inventories of learning styles were associated with personal and contextual factors such as academic discipline, prior education, age and gender, which may have significant relationships to teaching methods [50]. In other study it was found that personality, education, profession, job role and individual adaptive competencies are responsible for shaping learning style [38]. 
Hall \& Moseley gave direction to the much-debated field of cognitive and learning styles [72]. They proposed that learning style research should help the individual to overcome a particular style, and thus the focus should be on strategies rather than labeling an individual with a particular style, which can limit the learner's ambition. Instead, descriptions of learning styles should be tools used to break the chains of habit and limitation. Moreover, potential future learning style research should move in the direction of exploring transitions in learning styles at various life stages. It should devise ways of integrating with pedagogical frameworks and interacting with individual learning differences and personalities in studies meant for evidence based publications [67]. There is also a need to devise feasible frameworks and pedagogies embedded in concepts of learning styles [35], [73].

\section{CONCLUDING REMARKS}

Grey areas have been identified as challenges for future cognitive style research. These include research methodology, valid and reliable measurement tools based on specific theoretical grounds in psychological cognitive theories, and applying proposed frameworks and models to actual classroom/organizational situations. Previous studies of cognitive styles have relied on quantitative, cross-sectional and single source designs and obtained information through self-reports, sample surveys and student samples. It is then necessary to focus on overarching conceptual clarifications of other individual differences using multi-method and multisource approaches. Collaboration among different regions should also be encouraged [74].

Cognitive style research should be supported by advancements in other fields and areas of psychology. Blazhenkova \& Kozhevnikov incorporated developments in research on the human visual system and developed a new model, the Object-Spatial Imagery and Verbal model, in line with the dimensions of the old visual verbalizer style [75]. Similarly, Thomas \& McKay investigated verbalizer-visualizer styles and their measurement and proposed a new dimension: visual-verbalizer bipolar [15]. In future research, the bipolarity of different cognitive styles should be questioned and evaluated because everyone is gifted with some degree of each style dimension [66]. Kozhevnikov, Hegarty and Mayer and Kozhevnikov, Kosslyn \& Shephard discovered that the visual system has distinct systems used to process objects' properties and spatial properties [76], [77]. They have recommended that future research should probe why people who are good at object imagery have a propensity not to develop and use their spatial imagery ability and vice-versa. Similarly, how can people who perform poorly in one of the imagery dimensions be helped so that they can use their less-developed imagery skills more effectively?

There is also evidence that the social environment plays an important role in the development of different cognitive styles. Researchers have found empirical evidence that field-independent and fielddependent cognitive styles originate and develop in social environments and social settings. Field-dependent children become field-independent with exposure to technology, culture and experience [78]. Individual differences that are responsible for school success, along with cognitive and learning styles, can minimize or maximize the effect of cognitive styles in school-based learning [17]. However, for this to happen, researchers should explore the relationship between cognitive styles and motivation, attention, selfregulation, self-efficacy and emotions [19].

The predictive ability of working memory in the prediction of learning outcomes in different subjects was identified by Alloway, Banner, and Smith [79]. Future research should explore interventions to help students with low working memory using interactions between cognitive style designs and strategies. In line to what being highlighted by Kozhevnikove, the integration of different cognitive styles into a unified theory embedded in cognitive and neuropsychological research, the solution of bipolarity constraints, the relationship between personality and environment, and the development of models for strategy choice and adaptability should all be addressed by cognitive style researchers [1]

\section{REFERENCES}

[1] Kozhevnikove, M., Cognitive Styles in the Context of Modern Psychology: Toward an Integrated Framework of Cognitive Style. Psychological Bulletin, 2007.

[2] Riding, R., Cognitive style and types of problem behaviour in boys in special schools. British Journal of Educational Psychology, 69(3), 307, 1999.

[3] Cools, E., \& Bellens, K., The onion model: Myth or reality in the field of individual differences psychology? Learning and Individual Differences, 22(4), 455-462. doi: 10.1016/j.lindif.2012.04.002, 2012.

[4] Smith, E. S., The Relationship Between Learning Style and Cognitive Style. Personality and Individual Differences, 30 (2001), 609-616, 2001. 
[5] Cassidy, S., Learning Styles: An overview of theories, models, and measures. Educational Psychology, 24(4), 419-444. doi: 10.1080/0144341042000228834, 2004.

[6] Smith, E. S., Learning Style':Framework and Instruments. Educational Psychology: An International Journal of Experimental Educational Psychology, 17(1-2), 51-63. doi: 10.1080/0144341970170103, 1997.

[7] Ausburn, L., J., \& Ausburn, F., B., Cognitive Styles: Some Information and Implications for Instructional Design. Educational Communication \& Technology, 26(4), 337-354, 1978.

[8] Shade, B., J., Afro-American Cognitive Style: A Variable in School Success. Review of Educational Research, 1982.

[9] Messick, S., Bridging cognition and personality in education: the role of style in performance and development. European Journal of Personality, 10 (5), 353-376. doi: 10.1002/(sici)1099-0984(199612)10:5<353:: aid-per268>3.0.co;2-g, 1996.

[10] Thornell, J., G., Research on Cognitive Styles: Implications for Teaching and Learning, 1976.

[11] Peterson, E. R., Deary, I. J., \& Austin, E. J., Are intelligence and personality related to verbal-imagery and wholistic-analytic cognitive styles? Personality and Individual Differences, 39(1), 201-213. doi: 10.1016/j.paid.2005.01.009, 2005.

[12] Riding, R., J. and Sadler-Smith, Eugene (1997). Cognitive style and learning strategies: some implications for training design, 1997.

[13] Riding, R., \& Agrell, T., The Effect of Cognitive Style and Cognitive Skills on School Subject Performance. Educational Studies, 23(2), 311-323. doi: 10.1080/0305569970230213, 1997

[14] Riding, R. J., \& Al-Salih, N., Cognitive Style and Motor Skill and Sports Performance. Educational Studies, 26(1), 19-32, 2000.

[15] Thomas, P. R., \& McKay, J. B., Cognitive styles and instructional design in university learning. Learning and Individual Differences, 20(3), 197-202. doi: 10.1016/j.lindif.2010.01.002, 2010.

[16] Tinajero, C., Lemos, S., Maria, Araujo, M., Ferraces, M., Jose, \& Paramo, F., Cognitive Style and Learning Strategies as Factors Which Affect Academic Achievement of Brazilian University Students. Psicologia: Reflexao e Critica, 25(1), 105-113, 2012.

[17] Tinajero, C., \& Paramo, M. F., Educational implications of field dependence-independence: In answer to Bagley and Mallick. British Journal of Educational Psychology, 68(4), 589-589, 1998.

[18] Onyejiaku, F. O., Cognitive Styles, Instructional Strategies, and Academic Performance. The Journal of Experimental Education, 51(1), 31-37, 1982.

[19] Nicolaou, A. A., \& Xistouri, X., Field Dependence/Independene Cognitive Style and Problem Posing:An Investigation with Sixth Grade Students. Educational Psychology: An International Journal of Experimental Educational Psychology, 31(5), 611-627. doi: 10.1080/01443410.2011.586126, 2011.

[20] Riding, R., J., \& Al-Hajji, J., Cognitive Style and Behaviour in Secondary School Pupils in Kuwait. Educational Research(42-1), 29-42. doi: 10.1080/001318800363890, 2000.

[21] Angeli, C., Examining the effects of field dependence-independence on learners' problem-solving performance and interaction with a computer modeling tool: Implications for the design of joint cognitive systems. Computers and Education, 62, 221-230, 2012.

[22] Chiu, L.-H., The Relation of Cognitive Style and Manifest Anxiety to Academic Performance Among Chinese Children. The Journal of Social Psychology, 125(5), 667-669, 2001.

[23] Martinsen, Ø. L., \& Diseth, Å., The Assimilator-Explorer Cognitive Styles: Factor Structure, Personality Correlates, and Relationship to Inventiveness. Creativity Research Journal, 23(3), 273-283. doi: 10.1080/10400419.2011.595998, 2011.

[24] Huang, M.-S., \& Byrne, B., Cognitive Style and Lateral Eye Movements. British Journal of Psychology, 69, 85-90, 1978.

[25] Oliveri, S., Incorpora, C., Genevini, M., Santagostino, L., Tettamanti, L., Antonietti, A., \& Risoli, A., Clinical investigation of cognitive styles in patients with acquired brain damage. Neuropsychol Rehabil, 22(3), 362-373. doi: 10.1080/09602011.2011.647416, 2012.

[26] Ziętek, A. A., \& Roehr, K., Metalinguistic knowledge and cognitive style in Polish classroom learners of English. System, 39(4), 417-426. doi: 10.1016/j.system.2011.05.005, 2011.

[27] Höffler, T. N., \& Schwartz, R. N., Effects of pacing and cognitive style across dynamic and non-dynamic representations. Computers \& Education, 57(2), 1716-1726. doi: 10.1016/j.compedu.2011.03.012, 2011.

[28] Mampadi, F., Chen, S. Y., Ghinea, G., \& Chen, M.-P., Design of adaptive hypermedia learning systems: A cognitive style approach. Computers \& Education, 56(4), 1003-1011. doi: 10.1016/j.compedu.2010.11.018, 2011.

[29] Bird, E., Romanelli, F., \& Ryan, M., Learning styles: a review of theory, application, and best practices. [Article]. American Journal of Pharmaceutical Education, 73(1), 2009.

[30] Vorhaus, J., Learning Styles in Vocational Education and Training, 2010.

[31] Van Doorn, K., McManus, F., \& Yiend, J., An analysis of matching cognitive-behavior therapy techniques to learning styles. J Behav Ther Exp Psychiatry, 43(4), 1039-1044. doi: 10.1016/j.jbtep.2012.05.001, 2012.

[32] Cuthbert, P. F., The student learning process: Learning styles or learning approaches? Teaching in Higher Education, 10(2), 235-249. doi: 10.1080/1356251042000337972, 2005.

[33] Vermunt, J., \& Vermetten, Y., Patterns in Student Learning: Relationships Between Learning Strategies, Conceptions of Learning, and Learning Orientations. Educational Psychology Review, 16(4), 359-384. doi: 10.1007/s10648-004-0005-y, 2004. 
[34] Slack, N., \& Norwich, B., Evaluating the Reliability and Validity of $\mathrm{s}$ Learning Styles Inventory: a Classroom-Based Study. Educational Research, 49(1), 51-63. doi: 10.1080/00131880701200765, 2007.

[35] Miller, L. M., Using learning styles to evaluate computer-based instruction. Computers in Human Behavior, 21(2), 287-306. doi: 10.1016/j.chb.2004.02.011, 2005.

[36] Reio, T. G., An Examination of the Factor Structure and Construct Validity of the Gregorc Style Delineator. Educational and Psychological Measurement, 66(3), 489-501. doi: 10.1177/0013164405282459, 2006.

[37] Bergsteiner, H., Avery, G. C., \& Neumann, R., Kolb's experiential learning model: critique from a modelling perspective. Studies in Continuing Education, 32(1), 29-46. doi: 10.1080/01580370903534355, 2010.

[38] Kolb, D., A., \& Boyatzis, R. E., Experiential Learning Theory: Previous Research and New Directions. In R. J. Sternberg \& L. F. Zhang (Eds.), Perspectives on cognitive, learning, and thinking styles. NJ: Lawrence Erlbaum. 2000.

[39] Platsidou, M., \& Metallidou, P., Validity and Reliability Issues of Two Learning Inventories in a Greek Sample: Kolb's Learning Style Inventory and Felder \& Solomon's Index of Learning Styles. International Journal of Teaching and Learning in Higher Education, 20(3), 324-335, 2009.

[40] Brew, C. R., Kolb's Learning Style Instrument: Sensitive to Gender. Educational and Psychological Measurement, 62(2), 373-390. doi: 10.1177/0013164402062002011, 2002.

[41] Zwanenberg, N. V., Wilkinson, L. J., \& Anderson, A., Felder and Silverman's Index of Learning Styles and Honey and Mumford's Learning Styles Questionnaire: How Do They Compare and Do They Predict Academic Performance? Educational Psychology: An International Journal of Experimental Educational Psychology, 20(3), 365-380. doi: 10.1080/713663743, 2000

[42] Busato, V. V., Prins, F. J., Elshout, J. J., \& Hamaker, C., Learning styles: A cross-sectional and longitudinal study in higher education. British Journal of Educational Psychology, 68, 427-427, 1998.

[43] Riener, C., \& Willingham, D., The Myth of Learning Styles. Change: The Magazine of Higher Learning, 42(5), 32-35. doi: 10.1080/00091383.2010.503139, 2010.

[44] Leite, W. L., Svinicki, M., \& Shi, Y., Attempted Validation of the Scores of the VARK: Learning Styles Inventory With Multitrait-Multimethod Confirmatory Factor Analysis Models. Educational and Psychological Measurement, 70(2), 323-339. doi: 10.1177/0013164409344507, 2010.

[45] Rohrer, D., \& Pashler, H., Learning styles: where's the evidence? Med Educ, 46(7), 634-635. doi: 10.1111/j.13652923.2012.04273.x, 2012.

[46] Norman, G., When will learning style go out of style? [Editorial]. Adv Health Sci Educ Theory Pract, 14(1), 1-4. doi: 10.1007/s10459-009-9155-5, 2009.

[47] Dunn, R., Learning Style: State of Science. Theory into Practice, 23(1 Matching Teaching and Learning Styles), 10-19, 1984.

[48] Dunn, R., Survey Researh on Learning Styles. Educational Leadership, 46(6). doi:www.ascd.org/ASCD/pdf/journals/ed_lead/el_198903_dunn.pdf, 1989.

[49] Jones, C., Reichard, C., \& Mokhtari, K., Are Students' Learning Styles Discipline Specific? Community College Journal of Research and Practice, 27(5), 363-375. doi: 10.1080/713838162, 2003.

[50] Vermunt, J. D., Relations Between Student Learning Patterns and Personal and Contextual Factors and Academic performance. Higher Education, 49(3), 205-234. doi: 10.1007/s10734-004-6664-2, 2005.

[51] Threeton, M., D., \& Walter, R., A., The Relationship Between Personality Type and Learning Style: A Study of Automotive Technology Students. Journal of Industrial Teacher Education, 46(2), 48-74, 2009.

[52] Akbulut, Y., \& Cardak, C. S., Adaptive educational hypermedia accommodating learning styles: A content analysis of publications from 2000 to 2011. Computers \& Education, 58(2), 835-842. doi: 10.1016/j.compedu.2011.10.008, 2012.

[53] Lurea, C., Neascsu, I., Safta, C. G., \& Suditu, M., The Study of the Relation Between the Teaching Methods and the Learning Styles-The Impact Upon Students' Academic Conduct. Procedia Social and Behavioral Sciences, 11(2011), 256-260. doi: 10.1016/j.sbspro.2011.01.072, 2011.

[54] Kinshuk, Liu, T.-C., \& Graf, S., Coping with mismatched courses: students' behaviour and performance in courses mismatched to their learning styles. Educational Technology Research and Development, 57(6), $739-752$. doi: 10.1007/s11423-009-9116-y, 2009.

[55] Ozgur, S. D., Temel, S., \& Yilmaz, A., The Effect of Learning Styles of Preservice Chemistry Teachers on Their Perceptions of Problem Solving Skills and Problem Solving Achievements. Procedia - Social and Behavioral Sciences, 46, 1450-1454. doi: 10.1016/j.sbspro.2012.05.319, 2012.

[56] Mehrdad, A. G., \& Ahghar, M., Learning styles and learning strategies of left-handed EFL students. Procedia Social and Behavioral Sciences, 31, 536-545. doi: 10.1016/j.sbspro.2011.12.100, 2012.

[57] Huang, A. F., J. T. Wu, S. J. Yang, W. Y. Hwang, The Success of e-Portfolio-Based Programming Learning Style Diagnosis: Exploring the Role of a Heuristic Fuzzy Knowledge Fusion, in Expert Systems with Applications, 39(10), pp.8698-8706. DOI: 10.1016/j.eswa.2012.01.212, 2012.

[58] D'Amore, A., James, S., \& Mitchell, E. K., Learning styles of first-year undergraduate nursing and midwifery students: a cross-sectional survey utilising the Kolb Learning Style Inventory. [Research Support, Non-U.S. Gov't]. Nurse Educ Today, 32(5), 506-515. doi: 10.1016/j.nedt.2011.08.001, 2012 
[59] Law, D. C. S., \& Meyer, J. H. F., Relationships between Hong Kong students' perceptions of the learning environment and their learning patterns in post-secondary education. Higher Education, 62(1), 27-47. doi: 10.1007/s10734-010-9363-1, 2010.

[60] Hurst-Wajszczuk, K., Do they really get it? Using the Kolb LSI to reach every student. [Article]. Journal of Singing, 66(4), 421+, 2010.

[61] Alaoutinen, S., Heikkinen, K., \& Porras, J., Experiences of learning styles in an intensive collaborative course. International Journal of Technology and Design Education, 22 (1), 25-49. doi: 10.1007/s10798-010-9135-3, 2010.

[62] Graf, S., Lin, T., \& Kinshuk, The relationship between learning styles and cognitive traits - Getting additional information for improving student modelling. Computers in Human Behavior, 24(2), 122-137. doi: 10.1016/j.chb.2007.01.004, 2008.

[63] Graf, S., Liu, T.-C., Kinshuk, Chen, N.-S., \& Yang, S. J. H, Learning styles and cognitive traits - Their relationship and its benefits in web-based educational systems. Computers in Human Behavior, 25(6), 1280-1289. doi: 10.1016/j.chb.2009.06.005, 2009.

[64] Cook, D. A., Thompson, W. G., Thomas, K. G., \& Thomas, M. R., Lack of interaction between sensing-intuitive learning styles and problem-first versus information-first instruction: a randomized crossover trial. [Randomized Controlled Trial Research Support, Non-U.S. Gov't]. Adv Health Sci Educ Theory Pract, 14(1), 79-90. doi: 10.1007/s10459-007-9089-8, 2009.

[65] Cook, D. A., \& Smith, A. J., Validity of index of learning styles scores: multitrait-multimethod comparison with three cognitive/learning style instruments. Medical Education, 40(9), 900-907. doi: 10.1111/j.1365-2929.2006.02542.x, 2006.

[66] Evans , C., \& Smith, E., Eugene, Learning Styles in Education and Training: Problems, Politicisation and potential. Education +Training, 48(2), 77-83. doi: 10.1108/00400910610651728; 10.1108/00012531111135646; 10.1108/00012531011074726; 10.1108/14635781111150367, 2006.

[67] Evans, C., Cools, E., \& Charlesworth, Z. M, Learning in higher education - how cognitive and learning styles matter. Teaching in Higher Education, 15(4), 467-478. doi: 10.1080/13562517.2010.493353, 2010.

[68] Serife, A., A Conceptual Analaysis on the Approaches to Learning. Educational Sciences: Theory and Practice, 8(3), 707-720, 2008.

[69] Peterson, E., Armstrong, S., \& Rayner, S., Herding cats:In search of definitions of cognitive style and learning styles. Paper presented at the ELSIN Newsletter: An international forum, Winter 2008-2009 www.elsinnews.com. https://www.scss.tcd.ie/Tony.Redmond/2008ELSINnewsletter.pdf, 2009.

[70] Armstrong, S. J., Peterson, E. R., \& Rayner, S. G., Understanding and defining cognitive style and learning style: a Delphi study in the context of educational psychology. Educational Studies, 38(4), 449-455. doi: 10.1080/03055698.2011.643110, 2012.

[71] Wong, J., Kee-Kuok., Are the Learnign Styles of Asian International Students Culturally or Contexually Based? . International Education Journal, 4(4), 154-166, 2004.

[72] Hall, E., \& Moseley, D., Is there a role for learning styles in personalised education and training? International Journal of Lifelong Education, 24(3), 243-255. doi: 10.1080/02601370500134933, 2005.

[73] Baker, A. C., Jensen, P. J., \& Kolb, D. A., Conversation as Experiential Learning. In A. C. Baker, P. J. Jensen \& D. A. Kolb (Eds.), Conversational Learning An Experiential Approach To Knowledge Creation. Westport, Connecticut: Quorum Books, 2002.

[74] Cools, E., A reflection on the future of the cognitive style field: a proposed research agenda. [Review]. Reflecting Education, 5(2), 21-34, 2009.

[75] Blazhenkova, O., \& Kozhevnikov, M., The new object-spatial-verbal cognitive style model: Theory and measurement. Applied Cognitive Psychology, 23(5), 638-663. doi: 10.1002/acp.1473, 2009.

[76] Kozhevnikov, M., Hegarty, M., \& Mayer, R. E., Revising the Visualizer-Verbalizer Dimension: Evidence for Two Types of Visualizers. Cognition and Instruction, 20(1), 47-77, 2002.

[77] Kozhevnikov, M., Kosslyn, S., \& Shephard, J., Spatial Versus Object Visualizers: A New Characterization of Visual Cognitive Style. Memory and Cognition, 33(4), 710-726, 2005.

[78] Bagley, C., \& Mallick, K., Field independence, cultural context and academic achievement: A commentary. British Journal of Educational Psychology, 68(4), 581-581, 1998.

[79] Alloway, T., Packiam, Banner, G. E., \& Smith, P., Working Memory and Cognitive Styles in Adolescents Attainment. British Journal of Educational Psychology, 80, 567-591, 2010. 